\title{
Low impact of two LED colors on nocturnal insect abundance and bat activity in a peri-urban environment
}

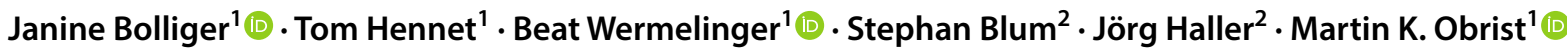

Received: 13 January 2020 / Accepted: 2 April 2020 / Published online: 9 April 2020

(c) The Author(s) 2020

\begin{abstract}
Artificial light at night (ALAN) is an important driver of change in ecological environments of the 21th century. We investigated the impact on nocturnal insect abundance and bat activity of two LED light colors (warm-white $2700 \mathrm{~K}$, cold-white $6500 \mathrm{~K}$ ) in a peri-urban environment. Bat activity (predominantly Pipistrellus pipistrellus) was largely driven by prey availability (insects), while insect abundance was responsive to nightly weather conditions (precipitation, temperature). Thus, both insects and bats were not differentially responsive to cold-white or warm-white LEDs. These findings are largely in contrast with literature, particularly for insects. However, as most published experiments on ALAN were conducted in areas that were lit solely for the purpose of the experiment, we would like to bring forward that (1) adaptation to environmental constraints may play a role in peri-urban environments that have been exposed to ALAN for many decades; or (2) impacts of cold-white LEDs on nocturnal insects may be lower than expected, because nocturnal insects adapted to low-light conditions may be put off by cold white light sources $(6500 \mathrm{~K})$.
\end{abstract}

Keywords Light pollution $\cdot$ Impact assessment $\cdot$ Flight-intersection trap $\cdot$ Batlogger $\cdot$ Artificial light at night; ALAN

\section{Introduction}

Artificial light at night (ALAN) is identified as an important driver of environmental change in the 21st century (Davies et al. 2012; Davies and Smyth, 2018; Hölker et al. 2010). Still an underestimated challenge for the ecological environment (Gaston et al. 2013; Guette et al. 2018; Lyytimaki 2013), ALAN may exacerbate already precarious conditions for nocturnal organisms (Desouhant et al. 2019; Fiorentin and Boscaro 2019; Owens et al. 2019; Tahkamo et al. 2019), and even leave traces into daytime (Knop et al. 2017). Recent reviews point out that artificial light at night impacts practically all aspects in the life cycle of nocturnal insects: orientation, movement, foraging pattern, mate choice, predator availability, larval development, physiological processes and, last, but not least, adaptive and behavioral traits (Desouhant et al. 2019; Owens et al. 2019; Owens and Lewis 2018).

Janine Bolliger

janine.bolliger@wsl.ch

1 WSL Swiss Federal Research Institute, Zürcherstrasse 111, 8903 Birmensdorf, Switzerland

2 EKZ Elektrizitätswerke Des Kanton Zürich, Dreikönigsstrasse 18, 8022 Zürich, Switzerland
Although new developments in LED technology provide long-lived and energy efficient lighting infrastructure (Djuretic and Kostic 2018), they have been the focus of many critical assessments claiming that LED might be particularly detrimental because their spectral composition peaks in the blue range to which many nocturnal insects appear sensitive ((Donners et al. 2018; Eccard et al. 2018; Grubisic et al. 2018; Longcore et al. 2015; Pawson and Bader 2014, but see Macgregor et al. (2019)). Replacing the older street lights with energy saving LEDs can also lead to brighter illumination. Thus, there is concern that the increased use of LEDs for street lights may save energy and financial costs at the expense of biodiversity (Stone et al. 2012). However, LED technology allows for selective adjustment of spectral composition of light emission (Pimputkar et al. 2009), potentially leading to a LED colour spectrum less attractive for insects (Longcore et al. 2015).

In this paper, we compared the impacts of two LED colors (cold-white $6500 \mathrm{~K}$, warm-white $2700 \mathrm{~K}$ with similar luminous fluxes $(1055,1150 \mathrm{~lm})$ ) and asked the following questions: To what extent do insect abundance and bat activity differ between cold-white $(6500 \mathrm{~K})$ and warm-white LEDs $(2700 \mathrm{~K})$ ? Do individual insect orders or bat guilds respond differently? We expected higher insect abundance at the cold 
white LEDs and consequently higher foraging activity of the light tolerant bats at these street luminaires.

\section{Material and methods}

\section{Study site and experiment}

We collected nocturnal insects and recorded bat acoustic signals during 44 nights between 22. 06. and 24. 08. 2017. The experimental site was located in a peri-urban community nearby Zürich, Switzerland (Uitikon Waldegg (Eduard-GutStrasse and Chapfstrasse, 47.3745 N, 8.4521 E)). The investigated LEDs had different spectral compositions but comparable luminous fluxes $(2700 \mathrm{~K}$ and $1050 \mathrm{~lm} ; 6500 \mathrm{~K}$ and $1150 \mathrm{~lm}$ ) and were installed in a street luminaire with a clear glass diffusor and facetted reflector. The street luminaires were divided into two sampling blocks at $295 \mathrm{~m}$ distance of each other (Fig. 1). One block was equipped with LEDs of $2700 \mathrm{~K}$ and the other with LEDs of $6500 \mathrm{~K}$ (Fig. 1a). Each sampling block consisted of seven street luminaires, of which the three central luminaires were used to sample insects (street light poles 196, 197, 267, 357, 272, 167; Fig. 1) and the outer two of the center luminaires also for recording bats (street-light poles 196, 267, 357, 167; Fig. 1; i.e., setup: buffer -insects+bats-insects-insects+bats-buffer). To account for site-specific characteristics at light poles, we swapped the locations of the LED colors on 20. 07. 2017 after 22 nights of sampling. The sampling continued for another 22 nights until 24. 08. 2017 (Fig. 1).

\section{Measuring the spectral compositions of street lights}

Light spectra were measured with a BTS256-EF BiTec Luxmeter (Gigahertz-Optik). The spectral sensor has a CMOS diode array spectro-radiometer with a spectral range of 380-750 nm (calibration uncertainty scotop. Illuminance: $\pm 2.2 \%$, pixel resolution: $1.5 \mathrm{~nm}$, optical resolution: $10 \mathrm{~nm}, \Delta \mathrm{x}$ uncertainty LED: \pm 0.004 , standard illuminant A: 0.002). Measurements were taken manually at one street-light pole per sampling block. The measurements were qualitative controls to visualize the different spectral components. For this purpose, the measuring head was aligned with the light source until the spectral value was no longer altered by extraneous light components. As the measurements were strictly qualitative, they did not allow for conclusions on light intensity distributions.

\section{Insect abundance at street lights}

Nocturnal insects were caught with flight-interception traps (Polytraps ${ }^{\circledR}$ (Benyahia et al. 2015; Gossner et al. 2013)), directly mounted on the street-light poles at a height of $3 \mathrm{~m}$
(Fig. 1b). The trapped insects were collected in a beaker filled with $40 \mathrm{ml}$ water with $0.5 \%$ Rocima GT antifouling detergent (Acima, Buchs, Switzerland). The traps were operational during nights only. This required two visits per trap each day: the traps were activated between 6 and 7 p.m. and the caught insects were collected between 6 and 7 a.m. the next day. During the sampling period, civil dusk started between 20:20 and 21:25, while civil dawn started between 04:50 and 06:02. All street lights were activated simultaneously during civil twilight and turned off during civil dawn. Insects collected were counted and sorted into eight taxonomic groups: Diptera, Coleoptera, Lepidoptera, Heteroptera, Hymenoptera, Trichoptera, Ephemeroptera and Neuropterida. Neuropterida are a recognized taxon, usually placed as superorder, and includes Neuroptera, Megaloptera and Raphidioptera.

\section{Bat activity at street lights}

Bats are nocturnal insectivores that use ultrasound echolocation for orientation and hunting (Schnitzler and Kalko 2001). This makes them acoustically conspicuous when using techniques that are sensitive to ultrasound (Griffin 1958). To monitor the presence of bats, a total of four batloggers (https://www.batlogger.com) were mounted at a height of $4 \mathrm{~m}$ on four street lights (Fig. 1a). The loggers automatically recorded echolocation calls from bats flying within a range of 10-30 m (species dependent), thus simultaneous recording of a single bat by two batloggers could be avoided. Echolocation calls of bats passing between 15 min before sunset and $15 \mathrm{~min}$ past sunrise triggered recordings of $1.5-10 \mathrm{~s}$ in length. This temporal setup was chosen to assure recording all bat activity while the street lights were operating. Acoustic recordings were then stored on SD memory cards as wav files for later analysis. The acoustic signals were recorded at a sampling rate of $312.5 \mathrm{kHz}$ and at 16-bit data depth. Once a week, the memory cards were retrieved to download the data and the batteries were recharged. The recorded signals of bats were processed using BatScope 3.2 (Obrist and Boesch 2018), a software program that cuts recorded vocalization sequences of bats into single echolocation calls, measures their temporal and spectral characteristics and statistically classifies them into species and genus. All species assignments were manually checked.

For analysis, bat records were grouped into (1) functional groups (Table 1 in Frey-Ehrenbold et al., (2013)): LRE $=$ Long-Range Echolocators (species foraging at long distances), MRE $=$ Mid-Range Echolocators (species that hunt flexibly closer to structures but also in the open) and SRE $=$ Short Range Echolocators (species that mainly hunt near or within complex landscape structures); (2) four RedList groups (LC: least concerns, NT: near threatened, VU: vulnerable, EN: endangered; (Bohnenstengel et al. 2014)), 
(a)

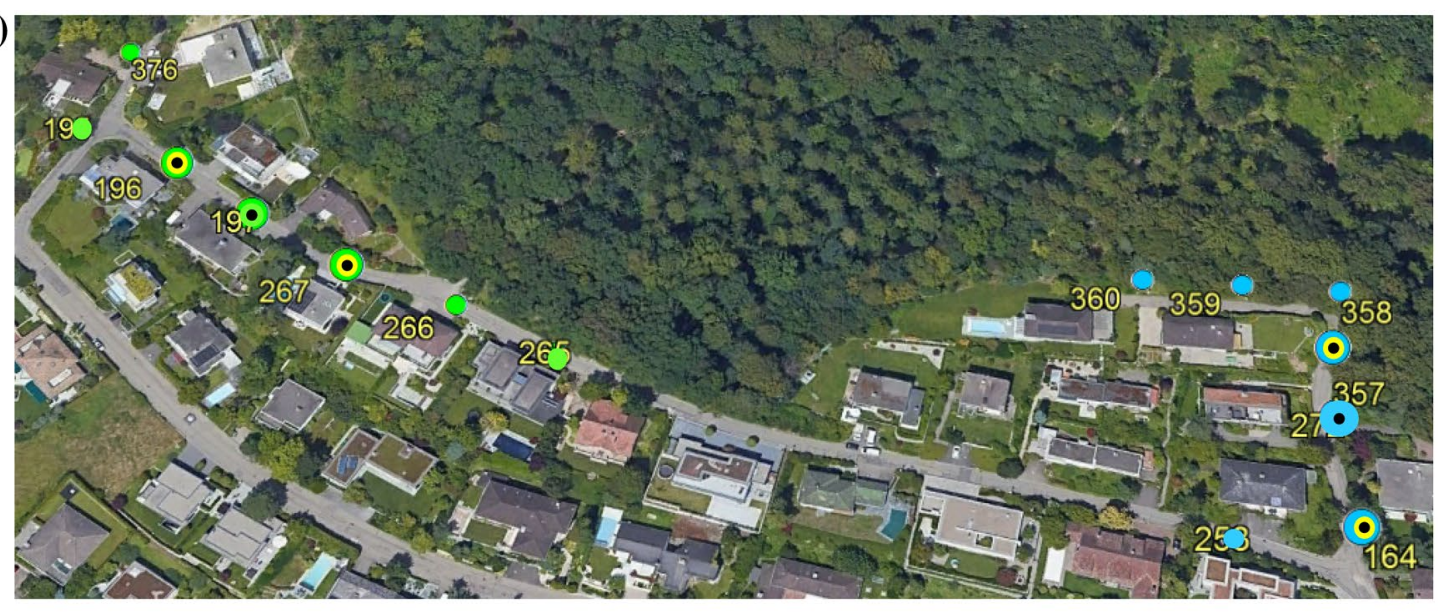

\begin{tabular}{l}
\begin{tabular}{l} 
Case-shaped housing \\
with LED \\
$2700 \mathrm{~K} \quad 22.6-19.7$ \\
\hline $6500 \mathrm{~K} \quad 20.7-24.8$
\end{tabular} \\
\hline
\end{tabular}

(b)

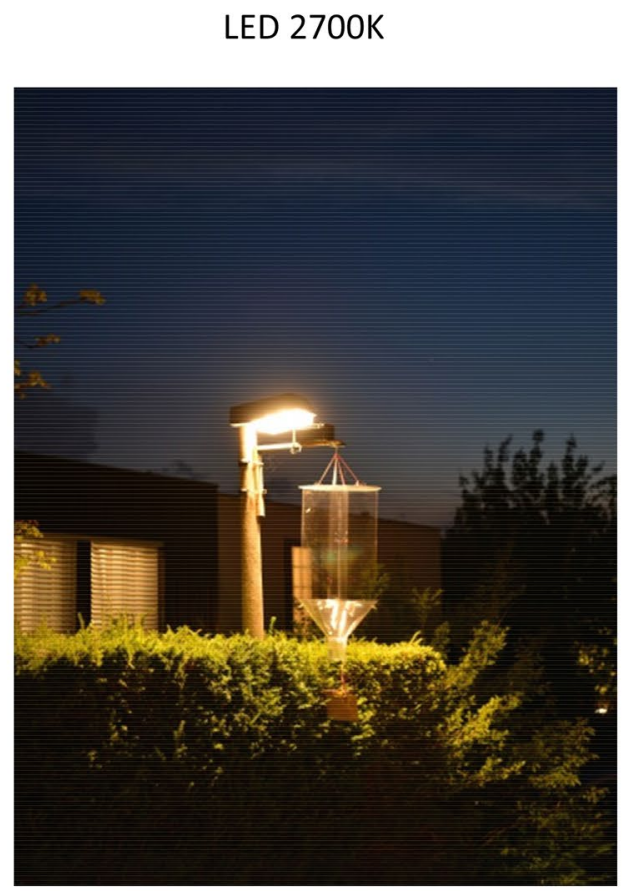

Fig. 1 a Experimental set up. Insects were sampled at three street lights (black dots) within two sampling blocks (green, blue), bordered by buffer lights (street lights without black dots). Yellow dots indicate street lights with bat loggers. Aerial image (C) 2019 Google, Google

$$
\begin{aligned}
& \text { Case-shaped housing } \\
& \text { with LED } \\
& \begin{array}{rr}
6500 \mathrm{~K} & 22.6 .-19.7 . \\
\hline 2700 \mathrm{~K} & 20.7 \cdot-24.8 .
\end{array}
\end{aligned}
$$

\section{LED $6500 \mathrm{~K}$}

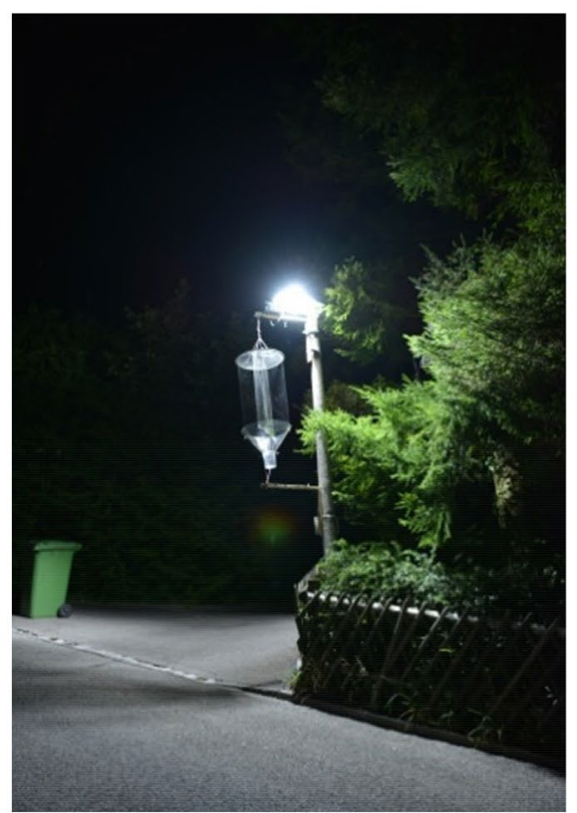

Earth Pro, US Dept. of State Geographer Data SIO, NOAA, US Navy, NGA, GEBCO, Image Landscape/Copernicus, b visual impression of the warm-white LED $(2700 \mathrm{~K})$ and cold-white LED color (6500 K), Photos M.K. Obrist. (Color figure online) 
Table 1 Number of insects (abundance) caught at street lights with warm-white $(2700 \mathrm{~K})$ and cold-white $(6500 \mathrm{~K})$ LEDs

\begin{tabular}{lccr}
\hline Insect orders & $2700 \mathrm{~K}$ & $6500 \mathrm{~K}$ & Total \\
\hline Diptera & 292 & 286 & 578 \\
Hymenoptera & 277 & 221 & 498 \\
Coleoptera & 112 & 132 & 244 \\
Heteroptera & 77 & 78 & 155 \\
Lepidoptera & 55 & 39 & 94 \\
Neuropterida & 15 & 25 & 40 \\
Trichoptera & 9 & 2 & 11 \\
Ephemeroptera & 5 & 0 & 5 \\
All insects & 842 & 783 & 1625 \\
\hline
\end{tabular}

and (3) six bat genera (Vespertilio spp., Nyctalus spp., Pipistrellus spp., Myotis spp., Eptesicus spp., Hypsugo spp.).

\section{Environmental variables}

The difference in insect abundance at two LED temperatures treatments $(2700 \mathrm{~K}$ and $6500 \mathrm{~K})$ was assessed relative to a set of environmental variables. Weather variables (nightly temperature means and nightly precipitation sums) were calculated from the nearby Meteoschweiz weather station Zürich-Affoltern (460 m a.s.1.), located at a distance of $11 \mathrm{~km}$ from the study site. The weather variables were calculated for a night which is defined between $9 \mathrm{pm}-5 \mathrm{am}$. The structure of the surrounding vegetation (mean of the vegetation height in a buffer of $10 \mathrm{~m}$ around each street light pole, Fig. 1) was assessed using a canopyheight model (Ginzler and Hobi 2015). The model relied on a $1 \mathrm{~m}$ digital elevation model that was combined with summer images from 2007 to 2012 for stereo matching. Optimized image matching, overall good performance and acceptable computation time make the canopy-height model suitable for nationwide applications (Ginzler and Hobi 2015).

Additionally, we used a unique identifier of the 44 sampled nights to mimic seasonal changes in bat and insect abundance. For bats, caught insect dry biomass was used as a proxy for available food resources for bats at street lights. The caught insects were pooled per night and dried in paper bags at $60{ }^{\circ} \mathrm{C}$ for $72 \mathrm{~h}$ in a Heraeus drying cabinet. After drying, the material was stored in a desiccator and weighed to an accuracy of $0.0001 \mathrm{~g}(0.1 \mathrm{mg})$ on a Mettler AE240 scale.

\section{Statistical analysis}

Generalized linear mixed-effect models (GLMM) were applied to assess the relative effects of street light regimes and other environmental variables on nocturnal insect abundance and species or guild specific bat activity. We used the function glmer in R package lme4 (Bates et al. 2015). GLMM are an extension of generalized linear models (GLMs) in which the linear predictor accounts for random effects in addition to fixed effects. The random effect included a unique identifier for the 44 sampled nights. Fixed effects included non-random quantities, encompassing nightly means of continuous variables (temperature, precipitation) as well as means for the surrounding vegetation. For insects, we obtained the number of caught insect per night and light source, an indicator for the attractiveness of a light source. For bats, we obtained nightly sums of bat passes at light sources, an indicator of bat activity.

\section{Model runs}

As we were considering count data (number of insects, number of bat passes), we fitted a GLMM models using a Poisson distribution. The count data were transformed (square root) and tests showed no overdispersion in the data structure (library DHARMa in R; https://cran.r-project.org/web/packa ges/DHARMa/vignettes/DHARMa.html). The number of insects and bat passes were pooled nightly according to LED colors. The final models contained variables correlated less than 0.6 (Pearson correlation) and had VIFs less than 1.8. VIF (variance inflation factor) is a measure to which degree a predictor is predicted from a linear regression given the other predictors (https://www.rdocumentation.org/packages/ regclass/versions/1.6/topics/VIF). In addition, information on model performance were reported: AIC, both marginal $\left(\mathrm{R}^{2} \mathrm{GLMM}(\mathrm{m})\right)$ and conditional $\left(\mathrm{R}^{2} \mathrm{GLMM}(\mathrm{c})\right) \mathrm{R}^{2}$ values.

\section{Results}

\section{LED characteristics}

The spectral composition of the two LED colors $(2700 \mathrm{~K}$, $6500 \mathrm{~K}$ ) ranged between 380 and $750 \mathrm{~nm}$ (Fig. 2). For LEDs at $2700 \mathrm{~K}$, the long-wave peak was located between 590 and $620 \mathrm{~nm}$ with a spectral irradiance (irradiance of a surface per unit wavelength $\left(\mathrm{W} * \mathrm{~m}^{-2} * \mathrm{~nm}^{-2}\right)$ ) of up to 0.15 and a minor shorter-wave peak at $450 \mathrm{~nm}$ with a spectral irradiance of 0.05 (Fig. 2a). In contrast, light colors of $6500 \mathrm{~K}$ peaked in the short-wave range at $450 \mathrm{~nm}$ with a spectral irradiance of up to 0.21 and the longer-wave range between 540 and $580 \mathrm{~nm}$ with a spectral irradiance up to 0.081 (Fig. 2 b).

\section{Insects}

We caught 1625 insects during 44 nights (Table 1). The most frequent insect orders included Diptera (578 individuals), 
(a)

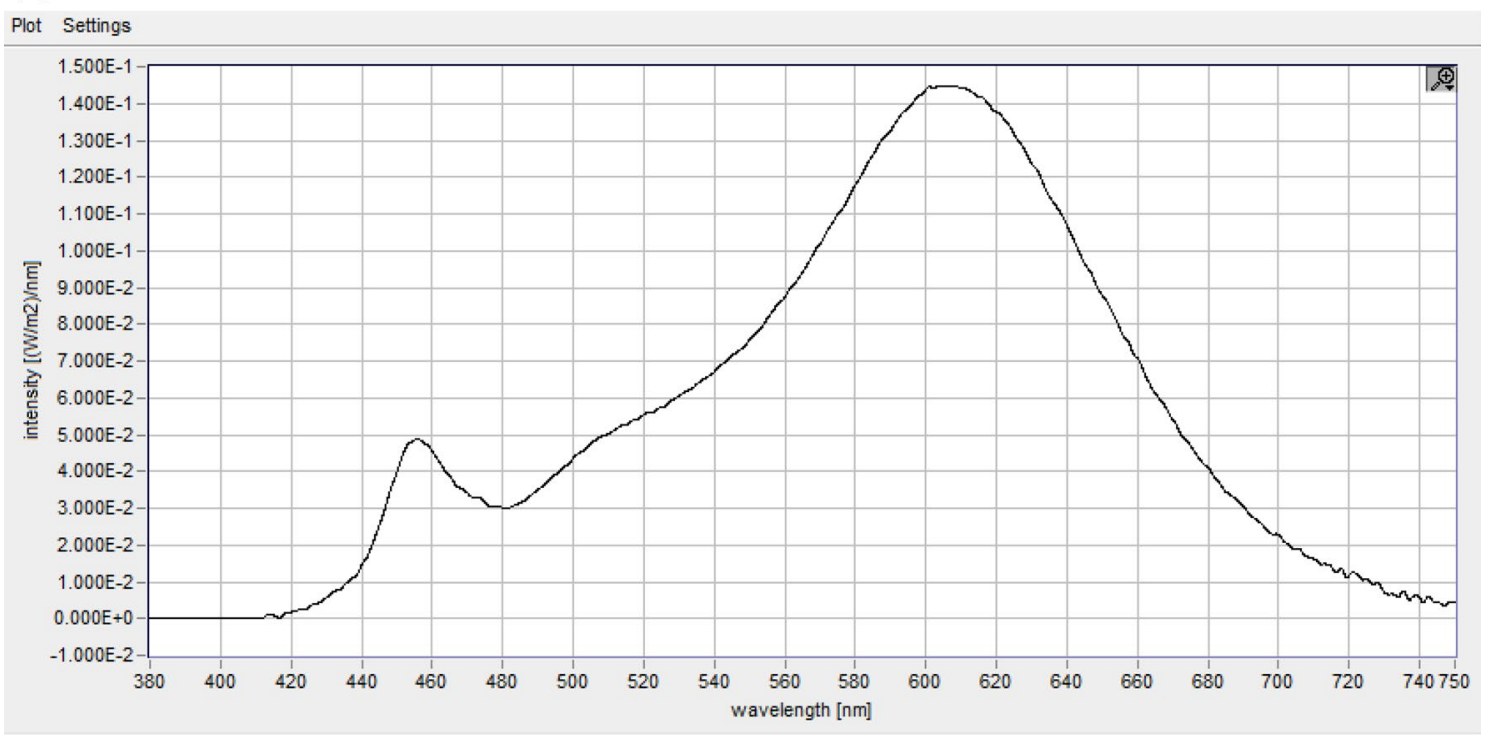

(b)

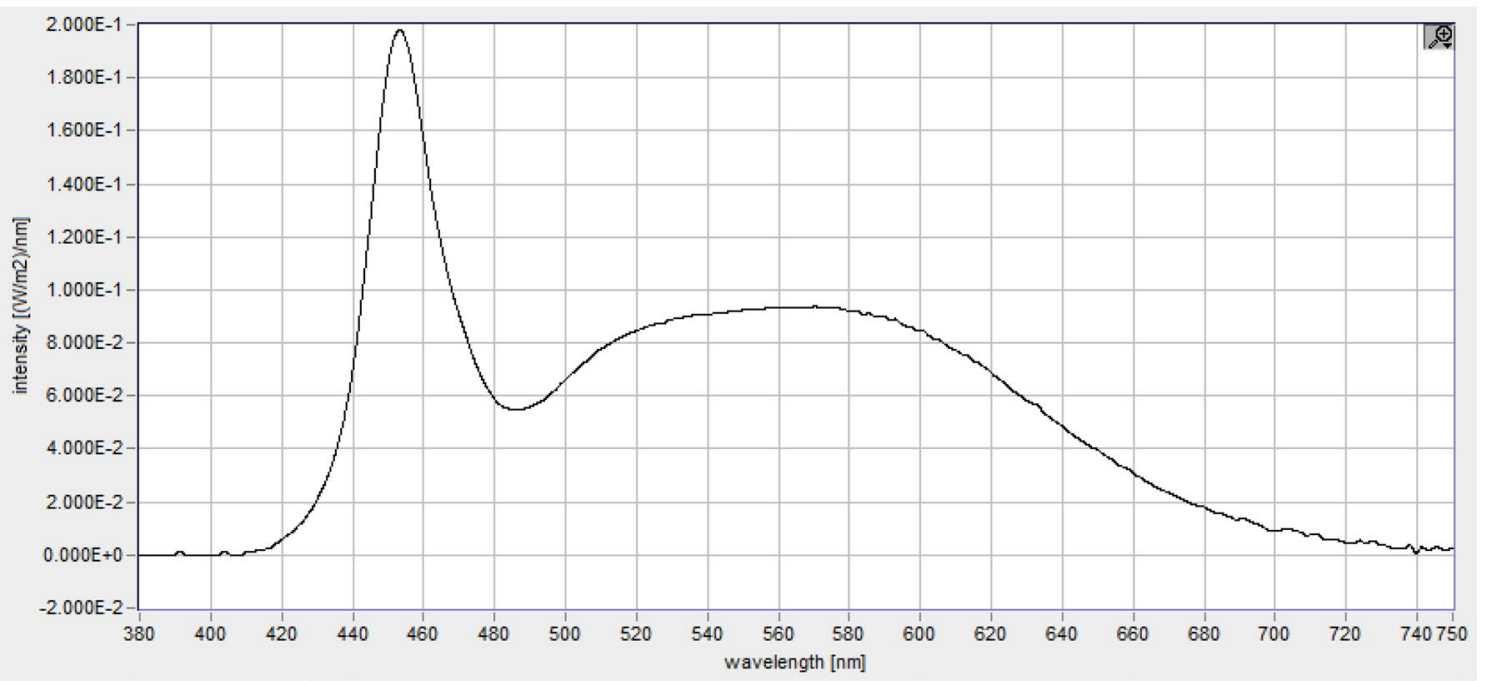

Fig. 2 Spectral composition of LEDs a $2700 \mathrm{~K}$, b $6500 \mathrm{~K}$

Hymenoptera (498), Coleoptera (244), Heteroptera (155) and Lepidoptera (94; Table 1). The insect groups Neuropterida, Trichoptera, Ephemeroptera contained a very small number of individuals and was omitted from further quantitative analyses (Table 1).

The strongest driver of insect communities was mean nightly temperature (Table 2). The number of insects caught at LED colors of $6500 \mathrm{~K}$ and $2700 \mathrm{~K}$ were very similar (Table 1), resulting in minimal differences between the total number of caught insects in cold-white versus warm-white LEDs (Fig. 3). Thus, no significant effects of light color on any of the insect groups was found (Table 2; Fig. 3).

\section{Bats}

We recorded 11629 identifiable bat passes during the 44 experiment nights (Table 3 ). Bat passes that could not be identified to at least guild levels were eliminated. The vast majority of recorded bats belonged to the guild of midrange echolocators (Table 4; Fig. 4), dominated mainly by Pipistrellus pipistrellus (Fig. 5), an urban exploiter and species of least concern in the Red List. Since the sample sizes of the remaining guilds (LRE and SRE, Table 4), as well as the other Red List categories was low (Table 5), our statistical analysis was restricted to the total number of all recorded bat passes (Table 6). Food abundance 
Table 2 Fixed effects of the GLMM analyses for all insects and individual insect groups

\begin{tabular}{|c|c|c|c|c|c|c|c|}
\hline & Estimate & Std. Error & $\mathrm{z}$ value & $\operatorname{Pr}(>|z|)$ & $\mathrm{R}^{2}$ (fixed) & $\mathrm{R}^{2}$ (total) & AIC \\
\hline \multicolumn{8}{|l|}{ All insects } \\
\hline Temperature & 0.059 & 0.024698 & 2.418 & $0.015^{*}$ & & & \\
\hline Precipitation & -0.005 & 0.007 & -0.767 & 0.443 & & & \\
\hline VHM & 0.003 & 0.011 & 0.254 & 0.799 & & & \\
\hline \multirow[t]{2}{*}{ LED $6500 \mathrm{~K}$} & -0.061 & 0.090 & -0.678 & 0.498 & & & \\
\hline & & & & & 0.11 & 0.48 & 783.8 \\
\hline \multicolumn{8}{|l|}{ Coleoptera } \\
\hline Temperature & 0.105 & 0.682 & 3.196 & $0.001 * *$ & & & \\
\hline Precipitation & -0.017 & 0.033 & -1.360 & 0.173 & & & \\
\hline VHM & 0.039 & 0.012 & 1.92 & $0.055()$. & & & \\
\hline \multirow[t]{2}{*}{ LED $6500 \mathrm{~K}$} & 0.009 & 0.169 & 0.055 & 0.956 & & & \\
\hline & & & & & 0.18 & 0.49 & 478.2 \\
\hline \multicolumn{8}{|l|}{ Diptera } \\
\hline Temperature & 0.024 & 0.023 & 1.025 & 0.305 & & & \\
\hline Precipitation & -0.002 & 0.007 & -0.372 & 0.710 & & & \\
\hline VHM & 0.009 & 0.016 & 0.594 & 0.553 & & & \\
\hline \multirow{2}{*}{ LED $6500 \mathrm{~K}$} & -0.006 & 0.121 & -0.048 & 0.962 & & & \\
\hline & & & & & 0.01 & 0.24 & 620.3 \\
\hline \multicolumn{8}{|l|}{ Heteroptera } \\
\hline Temperature & 0.219 & 0.040 & 5.429 & $0.000 * * *$ & & & \\
\hline Precipitation & 0.016 & 0.012 & 1.349 & 0.177 & & & \\
\hline VHM & -0.069 & 0.032 & -2.111 & $0.034 *$ & & & \\
\hline \multirow[t]{2}{*}{ LED $6500 \mathrm{~K}$} & -0.098 & 0.205 & -0.481 & 0.630 & & & \\
\hline & & & & & 0.24 & 0.76 & 376.4 \\
\hline \multicolumn{8}{|l|}{ Lepidoptera } \\
\hline Temperature & 0.010 & 0.040 & 0.224 & 0.823 & & & \\
\hline Precipitation & -0.007 & 0.013 & -0.562 & 0.574 & & & \\
\hline VHM & -0.020 & 0.034 & -0.590 & 0.555 & & & \\
\hline \multirow[t]{2}{*}{ LED $6500 \mathrm{~K}$} & -0.249 & 0.248 & -1.003 & 0.316 & & & \\
\hline & & & & & 0.01 & 0.03 & 328.5 \\
\hline \multicolumn{8}{|l|}{ Hymenoptera } \\
\hline Temperature & 0.113 & 0.070 & 1.600 & 0.109 & & & \\
\hline Precipitation & 0.039 & 0.021 & -1.808 & $0.070()$. & & & \\
\hline VHM & -0.032 & 0.022 & -1.406 & 0.159 & & & \\
\hline \multirow[t]{2}{*}{ LED $6500 \mathrm{~K}^{\mathrm{a}}$} & -0.069 & 0.157 & -0.437 & 0.662 & & & \\
\hline & & & & & 0.16 & 0.54 & 478.7 \\
\hline
\end{tabular}

Number of caught insects as a function of LEDs of two spectral compositions and other environmental variables. Temperature: mean nightly temperature; precipitation: nightly precipitation sum,

$V H M$ mean vegetation height surrounding the light poles; $R^{2}$ (fixed) contribution of fixed factors in reducing the overall model variability, $R^{2}$ (total) total $\mathrm{R}^{2}$ (fixed and random factors)

Statistical levels of significance: $(* * *)<0.001,(* *)<0.01,(*)<0.05,()<$.

${ }^{a}$ LED-2700 is the default for comparison. A negative coefficient indicates that fewer insects were observed at lights with $6500 \mathrm{~K}$ (cold white) compared to $2700 \mathrm{~K}$ (warm white) (insect biomass) had the strongest influence on bat activity, while night weather (temperature, precipitation) and the color of LEDs did not play a role.

\section{Discussion}

\section{Insect and bat responses to two LED colors}

Mean nightly temperature was clearly the strongest driver of the number of caught insects in our study (Table 2). Contrary to our expectations, no statistically significant 

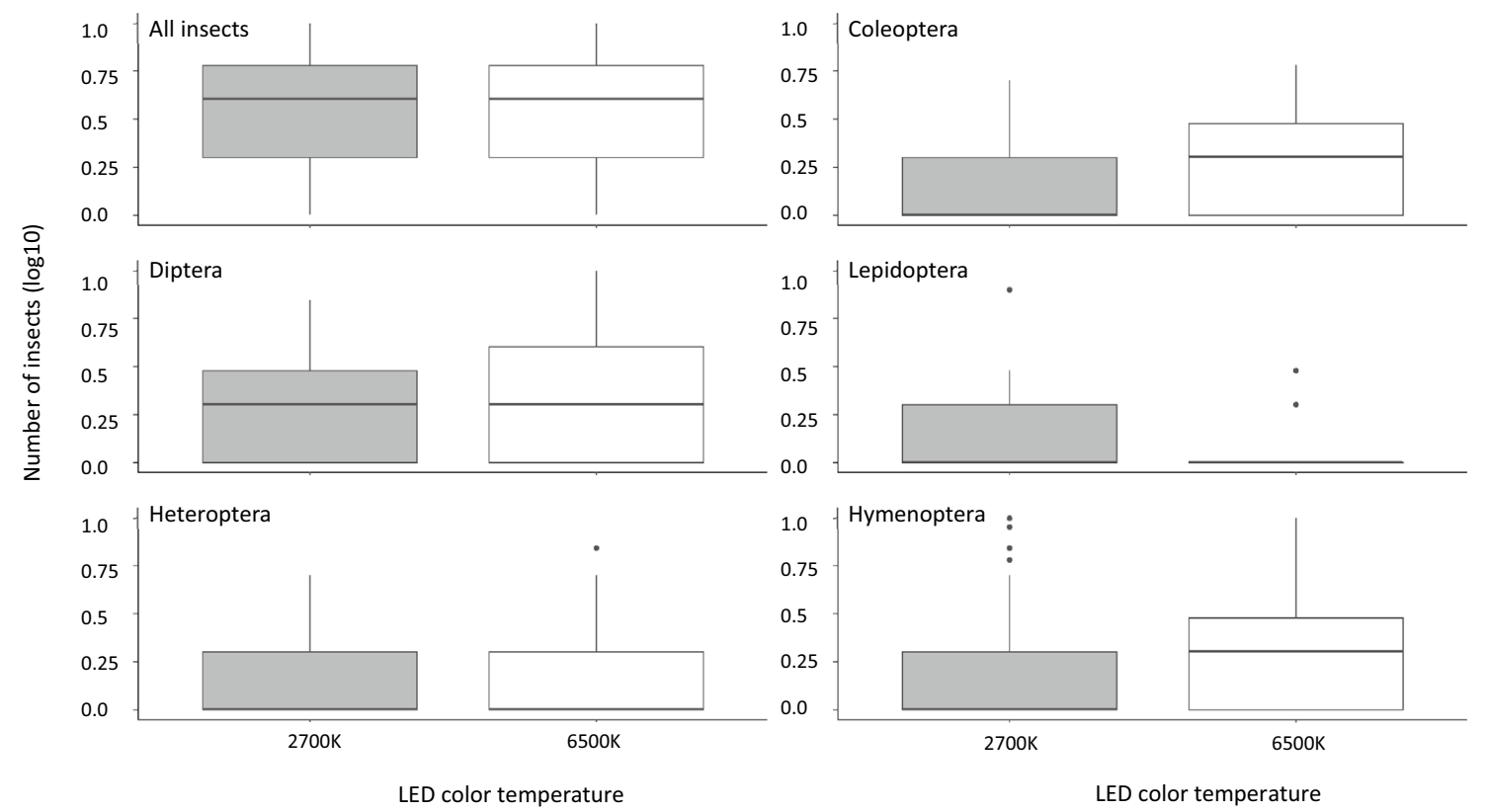

Fig. 3 Total number of insects, comparison between the warm-white LED (2700 K) and the cold-white LED color (6500 K). (Color figure online)

Table 3 Total number of bat passes at street lights with two LED colors

\begin{tabular}{lc}
\hline $\begin{array}{l}\text { LED color tem- } \\
\text { perature }\end{array}$ & $\begin{array}{l}\text { Number of } \\
\text { bat record- } \\
\text { ings }\end{array}$ \\
\hline $2700 \mathrm{~K}$ & 6487 \\
$6500 \mathrm{~K}$ & 5142 \\
Total & $\mathbf{1 1 , 6 2 9}$ \\
\hline
\end{tabular}

Table 4 Total number of bat passes for individual guilds

\begin{tabular}{lcc}
\hline $\begin{array}{l}\text { Systematic/ecological } \\
\text { group }\end{array}$ & LED color temperature & $\begin{array}{l}\text { Number of } \\
\text { bat record- } \\
\text { ings }\end{array}$ \\
\hline LRE & $2700 \mathrm{~K}$ & 48 \\
LRE & $6500 \mathrm{~K}$ & 35 \\
Total & & $\mathbf{8 3}$ \\
MRE & $2700 \mathrm{~K}$ & 6406 \\
MRE & $6500 \mathrm{~K}$ & 5024 \\
Total & & $\mathbf{1 1 , 4 3 0}$ \\
SRE & $2700 \mathrm{~K}$ & 33 \\
SRE & $6500 \mathrm{~K}$ & 83 \\
Total & & $\mathbf{1 1 6}$ \\
\hline
\end{tabular}

$L R E$ long-range echolocators; MRE mid-range echolocators; SRE short-range echolocators

difference in attraction between cold- white and warm- white LEDs was found for insects (Table 2). This is in disagreement with studies that report clear attraction to cold-white rather than warm-white LEDs, particularly for Lepidoptera
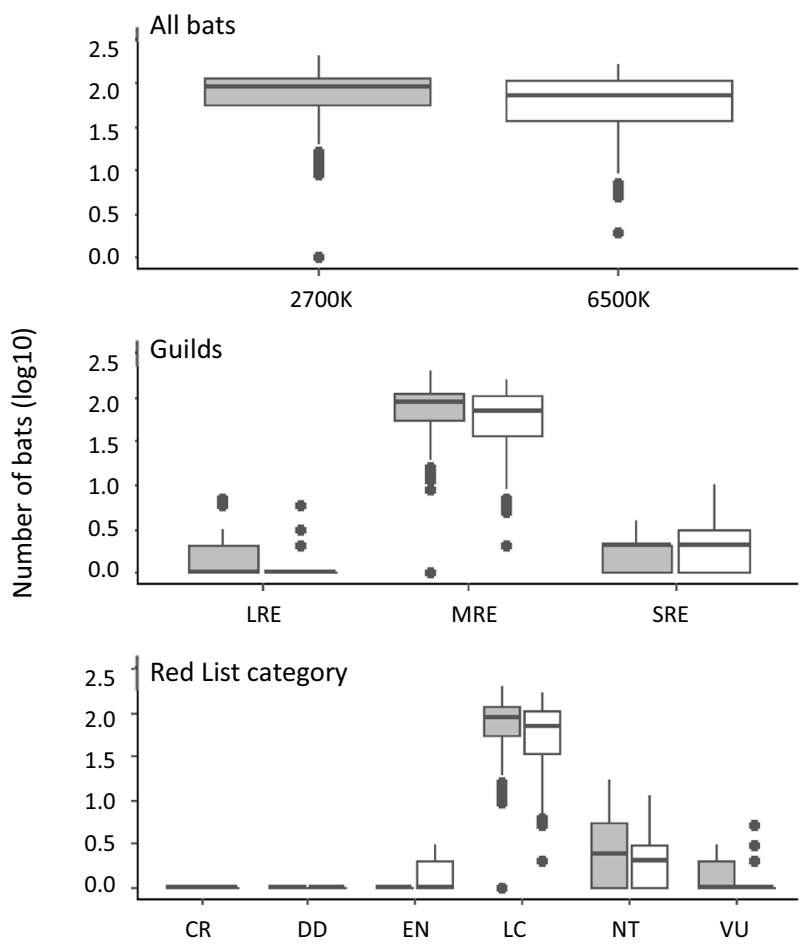

Fig. 4 a Bat activity (total number bat passes) for the warm-white LED $(2700 \mathrm{~K})$ and the cold-white LED color $(6500 \mathrm{~K})$; b Guilds: $L R E$ long-range echolocators; MRE mid-range echolocators; SRE short-range echolocators; c) Red Listed categories, $L C$ least concern; $N T$ near threatened; $V U$ vulnerable; $E N$ endangered. (Color figure online) 
Fig. 5 Activity of individual bat species at warm-white LED $(2700 \mathrm{~K})$ and cold-white LEDs $(6500 \mathrm{~K})$

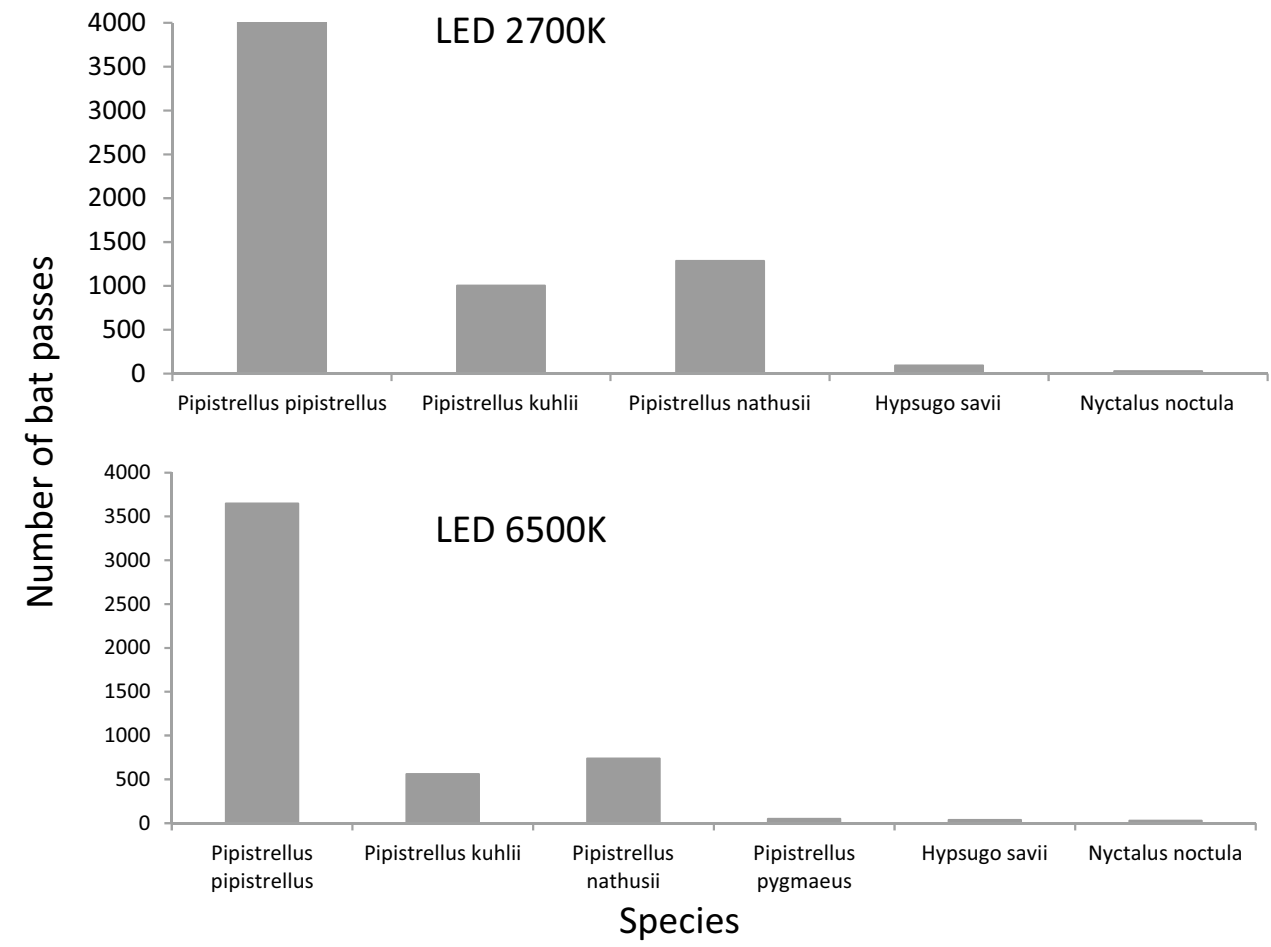

Table 5 Total number of bat passes according to Red List categories

\begin{tabular}{lcc}
\hline Red list category & LED color temperature & $\begin{array}{c}\text { Number of } \\
\text { bat passes }\end{array}$ \\
\hline LC & $2700 \mathrm{~K}$ & 6296 \\
LC & $6500 \mathrm{~K}$ & 4958 \\
Total & & $\mathbf{1 1 , 2 5 4}$ \\
VU & $2700 \mathrm{~K}$ & 26 \\
VU & $6500 \mathrm{~K}$ & 34 \\
Total & & $\mathbf{6 0}$ \\
NT & $2700 \mathrm{~K}$ & 157 \\
NT & $6500 \mathrm{~K}$ & 130 \\
Total & & $\mathbf{2 8 7}$ \\
EN & $2700 \mathrm{~K}$ & 7 \\
EN & $6500 \mathrm{~K}$ & 17 \\
Total & & $\mathbf{2 4}$ \\
\hline
\end{tabular}

$L C$ least concern; $N T$ near threatened; $V U$ vulnerable; $E N$ endangered

(Somer-Yeates et al. 2017; van Geffen et al. 2015; van Langevelde et al. 2011, but see (Longcore et al. 2015; Macgregor et al. 2019)).

Reasons may be manifold. While we may exclude factors related to the technical set-up of the experiment, as the street light experiment was designed in close collaboration with professional lighting engineers who have the required knowledge and access to the required infrastructure to support our research, there may be confounding factors as
ALAN is an aggregated measure that may represent many different human pressures (Ouyang et al. 2017). First, declining habitat size and quality are prominent examples of negative human pressures that may affect insects in peri-urban areas (Wenzel et al. 2019). Second, nocturnal insects are well adapted to low-light vision based on a range of physiological properties (Boyce 2019; Warrant 2017) such as highly sensitive photoreceptors (Honkanen et al. 2017). As a consequence, the long-term exposure of nocturnal communities to ALAN can lead to changes compared to communities that are less exposed to light (Altermatt and Ebert 2016; van Grunsven et al. 2019). Specifically, Altermatt and Ebert (2016) showed evidence that the response to ALAN exposure may result in reduced flight-to-light behavior in light-exposed urban moth populations compared to moths in dark areas. In the long term, lowered mobility negatively impacts competitiveness due to reduced foraging, dispersal or pollination (Altermatt and Ebert 2016; Knop et al. 2017), thus impacting ecosystem processes and functions (van Grunsven et al. 2019). Given that our study area has been exposed to ALAN for at least 40-50 years, it may thus well be that today's insect community has already undergone this selective process towards less light sensitive insectseven if exposed "only" to HPS light sources for the majority of these 40-50 years.

Bat activity was comparably high as could be expected in a suburban environment with streetlights (Rydell1992). Bats were recorded on average 66 times per batlogger and night. This number is rather low compared to the activity 
Table 6 Number of bat passes as a function of two LED spectral compositions and other environmental variables

\begin{tabular}{lrlrllll}
\hline All bats & Estimate & Std. Error & $\mathrm{z}$ value & $\operatorname{Pr}(>|\mathrm{z}|)$ & $\mathrm{R}^{2}$ (fixed) & $\mathrm{R}^{2}$ (total) & AIC \\
\hline Temperature & 0.024 & 0.030 & 0.808 & 0.419 & & & \\
Precipitation & -0.015 & 0.011 & -1.371 & 0.170 & & \\
VHM & -0.034 & 0.042 & -0.817 & 0.414 & & \\
Insect biomass & 6.872 & 1.799 & 3.821 & $0.000(* * *)$ & & \\
LED-6500K $^{\mathrm{a}}$ & -0.183 & 0.126 & -1.452 & 0.146 & &
\end{tabular}

0.17

1790.8

Temperature mean nightly temperature; precipitation nightly precipitation sum; mean VHM mean vegetation height surrounding the light poles; insect biomass dry biomass of insects; $R^{2}$ fixed contribution of fixed factors to reduce the overall model variability, $R^{2}$ (total) total $\mathrm{R}^{2}$ (fixed and random factors)

Statistical levels of significance: $(* * *)<0.001,(* *)<0.01,(*)<0.05,()<$.

${ }^{a}$ LED-2700 $\mathrm{K}$ is the default for comparison. The negative coefficient indicates that fewer bat passes were observed at lights with $6500 \mathrm{~K}$ (cold white) compared to lights with $2700 \mathrm{~K}$ (warm white) found in another survey in more rural but lit settlements, that showed an average of 318 passing bats $(\mathrm{N}=312$ batlogger nights; MK Obrist, pers.comm.). Then again, in yet another study we only achieved an average of 8 recordings at two unlit sites $(\mathrm{N}=90$ batlogger nights; M.K. Obrist, pers. comm.). This indicated that the bats were still attracted to the lights, but to a lesser degree than expected. The fact that insect abundance was a significant driver of bat activity in our study indicated (Table 6), that the overall lower activity of bats may well be due to the rather low number of available insects at the study site.

The discrepancy between the low numbers of insects caught and the number of bat recordings surpassing these by an order of magnitude may be explained by two factors. The traps themselves were not actively attracting insects, but passively catching them by chance when hitting the trap panels. Thus it will by no means be indicative of absolute insect abundance around the street lights. The bats however were recorded in their total activity: throughout the night any bat passing along the lights would be 'on file'. Furthermore, individual bats can regularly be observed patrolling a certain foraging stretch. Doing so, individuals will have been recorded multiple times. Present technology does only allow in very specific cases to acoustically identify and separate individuals (Kazial et al. 2001; Obrist1995). Nevertheless, differential activity is indicative of the degree of foraging potential a specific location provides for bats.

Bats profited from insects at street lights (Table 6, positive correlation between bat passes and insect biomass). The dominating Pipistrellus pipistrellus, is a synanthropic species that is least disturbed by light (Spoelstra et al. 2017; Zeale et al. 2018). Selective filtering of bat species by ALAN has also been observed by Haddock et al. (2019), indicating that clutter adapted species are most intolerant to ALAN (Spoelstra et al. 2017). These unfortunately also comprise the species of highest conservation concern (Bohnenstengel et al. 2014). The fact that an unexpectedly high percentage $(98 \%)$ of the registered activity was attributed to light tolerant guild of MRE species leads us to the assumption, that ALAN may exert a competitive pressure on more light adverse species, as light tolerant species can better exploit food concentrated around street lights.

Our experiment did not show significant responses of bats and insects to the two different color temperatures tested. However, we still would stick to the recommendation of using longer wavelength illuminants (warm-white) to reduce likely adverse effects of ALAN. This avoids emitting light in the ultra-violet range that many insects are most attracted to, while simultaneously reducing skyglow in the vicinity of the lights (Gaston et al. 2012).

Acknowledgements We thank two anonymous reviewers who carefully commented on an earlier draft of this paper. We are grateful for the generous support of B. Rohner (WSL) for the statistical support. D. Schneider, A. Zberg and H. Paproth (WSL) helped in the entomology lab. The project was funded by CCES GeneMig with additional financial support from the Kanton Zürich (AWEL (V. Delb) and the Fachstelle Naturschutz des Kantons Zürich (P. Weber). The WSL Land use systems group and EKZ also supported us financially. The public works (TBA) of the Kanton Zürich and the communal administration of Uitikon are acknowledged for granting permission to conduct this research.

\section{Compliance with ethical standards}

Conflict of interest The authors declare that they have no conflict of interest.

Open Access This article is licensed under a Creative Commons Attribution 4.0 International License, which permits use, sharing, adaptation, distribution and reproduction in any medium or format, as long as you give appropriate credit to the original author(s) and the source, provide a link to the Creative Commons licence, and indicate if changes were made. The images or other third party material in this article are included in the article's Creative Commons licence, unless indicated otherwise in a credit line to the material. If material is not included in the article's Creative Commons licence and your intended use is not permitted by statutory regulation or exceeds the permitted use, you will need to obtain permission directly from the copyright holder. To view a copy of this licence, visit http://creativecommons.org/licenses/by/4.0/. 


\section{References}

Altermatt F, Ebert D (2016) Reduced flight-to-light behaviour of moth populations exposed to long-term urban light pollution. Biol Lett 12:20160111

Bates D, Machler M, Bolker BM, Walker SC (2015) Fitting linear mixed-effects models using lme4. J Stat Softw 67:1-48

Benyahia Y, Soldati F, Rohi L, Valladarès L, Maatouf N, Courtin O, El Antry S, Brustel H (2015) First survey of darkling beetles (Coleoptera, Tenebrionidae) of Talassemtane National Park, Western Rif. Morocco Check List 11:1778

Bohnenstengel T, Krättli H, Obrist MK, Bontadina F, Jaberg C, Ruedi M, Moeschler P, (2014) Rote Liste Fledermäuse. Gefährdete Arten der Schweiz, Stand, (2011) Bundesamt für Umwelt. Centre de Coordination Ouest pour l'étude et la protection des chauvessouris, Bern; Genève

Boyce PR (2019) The benefits of light at night. Build Environ $151: 356-367$

Davies TW, Bennie J, Gaston KJ (2012) Street lighting changes the composition of invertebrate communities. Biol Let 8:764-767

Davies TW, Smyth T (2018) Why artificial light at night should be a focus for global change research in the 21 st century. Glob Change Biol 24:872-882

Desouhant E, Gomes E, Mondy N, Amat I (2019) Mechanistic, ecological, and evolutionary consequences of artificial light at night for insects: review and prospective. Entomol Exp Appl 167:37-58

Djuretic A, Kostic M (2018) Actual energy savings when replacing high-pressure sodium with LED luminaires in street lighting. Energy 157:367-378

Donners M, van Grunsven RHA, Groenendijk D, van Langevelde F, Bikker JW, Longcore T, Veenendaal E (2018) Colors of attraction: Modeling insect flight to light behavior. Journal of Experimental Zoology Part a-Ecological and Integrative Physiology 329:434-440

Eccard JA, Scheffler I, Franke S, Hoffmann J (2018) Off-grid: solar powered LED illumination impacts epigeal arthropods. Insect Conserv Divers 11:600-607

Fiorentin P, Boscaro F (2019) A method for measuring the light output of video advertising reproduced by LED billboards. Measurement 138:55-33

Frey-Ehrenbold A, Bontadina F, Arlettaz R, Obrist MK (2013) Landscape connectivity, habitat structure and activity of bat guilds in farmland-dominated matrices. J Appl Ecol 50:252-261

Gaston KJ, Bennie J, Davies TW, Hopkins J (2013) The ecological impacts of nighttime light pollution: a mechanistic appraisal. Biol Rev 88:912-927

Gaston KJ, Davies TW, Bennie J, Hopkins J (2012) Reducing the ecological consequences of night-time light pollution: options and developments. J Appl Ecol 49:1256-1266

Ginzler C, Hobi ML (2015) Countrywide stereo-image matching for updating digital surface models in the framework of the Swiss National Forest Inventory. Remote Sens 7:4343-4370

Gossner MM, Lachat T, Brunet J, Isacsson G, Bouget C, Brustel H, Brandl R, Weisser WW, Muller J (2013) Current near-to-nature forest management effects on functional trait composition of saproxylic beetles in beech forests. Conserv Biol 27:605-614

Griffin DR (1958) The acoustic orientation of bats and men. Yale University Press, New Haven

Grubisic M, van Grunsven RHA, Manfrin A, Monaghan MT, Holker F (2018) A transition to white LED increases ecological impacts of nocturnal illumination on aquatic primary producers in a lowland agricultural drainage ditch. Environ Pollut 240:630-638
Guette A, Godet L, Juigner M, Robin M (2018) Worldwide increase in artificial light at night around protected areas and within biodiversity hotspots. Biol Cons 223:97-103

Haddock JK, Threlfall CG, Law B, Hochuli DF (2019) Light pollution at the urban forest edge negatively impacts insectivorous bats. Biol Cons 236:17-28

Hölker F, Moss T, Griefahn B, Kloas W, Voigt CC, Henckel D, Hänel A, Kappeler PM, Völker S, Schwope A, Franke S, Uhrlandt D, Fischer J, Klenke R, Wolter C, Tockner K (2010) The dark side of light - a transdisciplinary research agenda for light pollution policy. Ecol Soc 15:13

Honkanen A, Immonen EV, Salmela I, Heimonen K, Weckstrom M (2017) Insect photoreceptor adaptations to night vision. Philos Trans Royal Soc B-Biol Sci 372:9

Kazial KA, Burnett SC, Masters WM (2001) Individual and group variation in echolocation calls of big brown bats, Eptesicus fuscus (Chiroptera : Vespertilionidae). J Mammal 82:339-351

Knop E, Zoller L, Ryser R, Erpe CG, Horler M, Fontaine C (2017) Artificial light at night as a new threat to pollination. Nature 548:206

Longcore T, Aldern HL, Eggers JF, Flores S, Franco L, HirshfieldYamanishi E, Petrinec LN, Yan WA, Barroso AM (2015) Tuning the white light spectrum of light emitting diode lamps to reduce attraction of nocturnal arthropods. Philos Trans Royal Soc B-Biol Sci 370:20140125

Lyytimaki J (2013) Nature's nocturnal services: Light pollution as a non-recognised challenge for ecosystem services research and management. Ecosys Serv 3:E44-E48

Macgregor CJ, Pocock MJO, Fox R, Evans DM (2019) Effects of street lighting technologies on the success and quality of pollination in a nocturnally pollinated plant. Ecosphere 10:e 02550

Obrist MK (1995) Flexible bat echolocation-the influence of individual, habitat and conspecifics on sonar signal-design. Behav Ecol Sociobiol 36:207-219

Obrist MK, Boesch R (2018) BatScope manages acoustic recordings, analyses calls, and classifies bat species automatically. Can J Zool 96:939-954

Ouyang JQ, de Jong M, van Grunsven RHA, Matson KD, Haussmann MF, Meerlo P, Visser M, Spoelstra K (2017) What type of rigorous experiments are needed to investigate the impact of artificial light at night on individuals and populations? Glob Change Biol 23:E9-E10

Owens ACS, Cochard P, Durrant J, Farnworth B, Perkin EK, Seymoure B (2019) Light pollution is a driver of insect declines. Biol Conserv 241:108259

Owens ACS, Lewis SM (2018) The impact of artificial light at night on nocturnal insects: a review and synthesis. Ecol Evol $8: 11337-11358$

Pawson SM, Bader MKF (2014) LED lighting increases the ecological impact of light pollution irrespective of color temperature. Ecol Appl 24:1561-1568

Pimputkar S, Speck JS, DenBaars SP, Nakamura S (2009) Prospects for LED lighting. Nat Photonics 3:179-181

Rydell J (1992) Exploitation of insects around streetlamps by bats in Sweden. Funct Ecol 6:744-750

Schnitzler HU, Kalko EKV (2001) Echolocation by insect-eating bats. Bioscience 51:557-569

Somer-Yeates R, Hodgson D, McGregor PK, Spalding A, FfrenchConstant RH (2017) Shedding light on moths: shorter wavelengths attract noctuids more than geometrids. Biol Lett 9:20130376

Spoelstra K, van Grunsven RHA, Ramakers JJC, Ferguson KB, Raap T, Donners M, Veenendaal EM, Visser ME (2017) Response of bats to light with different spectra: light-shy and agile bat presence is affected by white and green, but not red light. Proc Royal Soc B-Biol Sci 284:20170075 
Stone EL, Jones G, Harris S (2012) Conserving energy at a cost to biodiversity? Impacts of LED lighting on bats. Glob Change Biol 18:2458-2465

Tahkamo L, Partonen T, Pesonen AK (2019) Systematic review of light exposure impact on human circadian rhythm. Chronobiol Int 36:151-170

van Geffen KG, van Eck E, de Boer RA, van Grunsven RHA, Salis L, Berendse F, Veenendaal EM (2015) Artificial light at night inhibits mating in a Geometrid moth. Insect Conserv Divers 8:282-287

van Grunsven RHA, Becker J, Peter S, Heller S, Holker F (2019) Long-Term Comparison of Attraction of flying insects to streetlights after the transition from traditional light sources to lightemitting diodes in Urban and Peri-Urban settings. Sustainability 11:6198

van Langevelde F, Ettema JA, Donners M, WallisDeVries MF, Groenendijk D (2011) Effect of spectral composition of artificial light on the attraction of moths. Biol Cons 144:2274-2281
Warrant EJ (2017) The remarkable visual capacities of nocturnal insects: vision at the limits with small eyes and tiny brains. Philos Trans Royal Soc B-Biol Sci 372:20160063

Wenzel A, Grass A, Belavadi VV, Tscharntke T (2019) How urbanization is driving pollinator diversity and pollination-a systematic review. Biol Conserv 241:108321

Zeale MRK, Stone EL, Zeale E, Browne WJ, Harris S, Jones G (2018) Experimentally manipulating light spectra reveals the importance of dark corridors for commuting bats. Glob Change Biol 24:5909-5918

Publisher's Note Springer Nature remains neutral with regard to jurisdictional claims in published maps and institutional affiliations. 